\title{
EXPERIMENTAL AND NUMERICAL INVESTIGATIONS OF GLASS CURTAIN WALLS SUBJECTED TO LOW- LEVEL BLAST LOADS
}

\author{
ADAM D. RALSTON ${ }^{1}$, DAVID C. WEGGEL ${ }^{1}$, MATTHEW J. WHELAN ${ }^{1} \&$ HONGBING FANG $^{2}$ \\ ${ }^{1}$ Department of Civil and Environmental Engineering, The University of North Carolina at Charlotte, USA. \\ ${ }^{2}$ Department of Mechanical Engineering and Engineering Science, \\ The University of North Carolina at Charlotte, USA.
}

\begin{abstract}
A series of three full-scale, nearly-conventional, curtain wall specimens were blast tested in the open arena of the Infrastructure Security and Emergency Responder Research and Training (ISERRT) Facility in Gastonia, NC. The specimens were subjected to low-level blast loads produced from the detonation of high explosives. Low-level blast loads, similar to those produced during the tests, are typical of small charge weights (i.e. satchel charges) at short-to-moderate standoffs. A simple finite element (FE) model that effectively represents the nonlinear dynamic response of glass curtain walls subjected to blast loads was developed, and simulation results were compared with the test results. It was shown that, with the judicious choice of modeling parameters, the FE model effectively represents the response of glass curtain walls subjected to blast loads while being computationally economical. The calibrated FE model was used to evaluate the efficacy of a nonlinear single-degree-of-freedom (NSDOF) design expression for analytically approximating the blast resistance of curtain wall systems. The design expression is based on a procedure in which a nonlinear resistance function of the system is input to an energy expression that models the maximum nonlinear dynamic deflection due to an 'impulsive' loading. It was shown that the maximum impulse predicted by the design expression, when the expression was used in conjunction with a satisfactory resistance function, compared reasonably well with the FE simulation results. The expression could be used as a starting point for design or to supplement more advanced models of curtain walls subjected to blast loads.

Keywords: finite element modeling, glass curtain wall, nonlinear dynamic response, open-arena blast testing
\end{abstract}

\section{INTRODUCTION}

The utilization of glass curtain walls is increasingly common in modern construction, not only in new buildings but also as a revitalizing solution for the retrofit of existing structures. Curtain walls have traditionally been considered architectural elements, whose lateral design is commonly dictated by prescribed wind loads. However, the increase in terrorist acts directed towards civilian targets has raised concerns about the definition of a 'low-risk' structure and has prompted more designers and building owners to examine the blast resistance of curtain walls.

This investigation was an extension of a long-term study in which a 'nearly-conventional' curtain wall system was evaluated as an economical façade option for situations that warrant supplying additional protection to building occupants from low-level blast overpressures and flying debris. A 'nearly-conventional' curtain wall, in this context, comprised conventional materials and components with two modifications: the use of laminated glass lites (in place of monolithic glass lites) that are structurally glazed to a conventional framing system (extruded aluminum mullions) with structural silicone sealant (in place of compression gaskets). The low-level blast loads considered in this work are representative of a satchel charge at short-to-moderate standoffs, resulting in overpressures that are near the acoustic limit (peak reflected overpressures are approximately twice the peak incident overpressures). 
Goals of this study were to develop a finite element (FE) model validated against experimental results from the open-arena blast tests performed and subsequently to investigate the efficacy of a simple nonlinear single-degree-of-freedom (NSDOF) design expression for approximating the blast resistance of curtain walls, as presented in Kennedy et al. [1]. In his work, Kennedy conducted material testing and a series of tests on full-scale curtain wall specimens and components [2]. The specimens were quasi-statically tested to failure to obtain complete resistance functions until the curtain wall specimens were considered to no longer serve as a protective barrier. Kennedy et al. [1] used the experimentally-obtained resistance functions as input to a simple nonlinear design expression (based on the conservation of energy of a NSDOF system) to model the maximum dynamic deflection of a curtain wall system subjected to an impulsive blast load.

Curtain wall components have received significantly more attention than curtain wall systems as a whole. The literature provides a wealth of references on the characteristics of monolithic and laminated glass, and the performance of laminated glass subjected to blast loads has been extensively studied in recent years [3-7]. Hooper et al. [8] performed full-

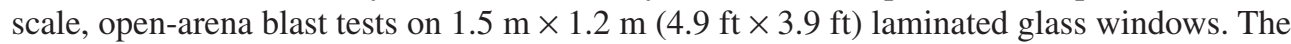
windows were loaded by $15 \mathrm{~kg}(33 \mathrm{lb})$ and $30 \mathrm{~kg}(66 \mathrm{lb})$ charges at standoffs of $10 \mathrm{~m}(32.8 \mathrm{ft})$ and $16 \mathrm{~m}(52.5 \mathrm{ft})$, respectively. The authors reported that the main failure mechanisms observed were de-bonding of the glass from the supporting framework at the silicone joints and delamination between the glass and polyvinyl butyral (PVB) interlayer. Researchers have also applied simulated blast loads to laminated glass specimens through the use of shock tubes [9]. Larcher et al. [10] used their results to validate a numerical model of laminated glass that produced accurate results up to and including interlayer failures. Due to the unique requirements associated with conducting open-arena blast tests, however, many researchers have turned to numerical methods to efficiently study the characteristics of laminated glass subjected to blast loads. Wei and Dharani conducted a series of studies [11-14] in which they developed an analytical model to predict the probability of failure of laminated glass panels subjected to blast loading. Numerical simulations have also been performed to produce pressure-impulse (P-I) diagrams for laminated glass in order to provide correlations between the blast load and the performance of the glass $[15,16]$. Validated numerical models allow researchers to efficiently conduct parametric studies to examine the influence of factors such as dimensions, glass thickness, interlayer thickness and boundary conditions on the dynamic response of laminated glass. Research has also been conducted on the effectiveness of structural silicone sealant in protective glazing applications [17, 18]. The effect of joint configuration, loading rate, and weathering on the performance and durability of silicone sealants has been evaluated.

Studies of complete curtain wall systems have traditionally been limited to static or cyclic dynamic loads. Recently, however, researchers have extended their efforts to include the nonlinear response of curtain wall systems subjected to impulsive (blast) loads [19-22]. Through the use of numerical simulations, Field et al. [23] examined the performance of a cablesupported curtain wall system subjected to blast loads. The authors described the challenge of achieving a balanced design due to the flexibility of the coupled system. They outlined the importance of capturing differential movements when analyzing/designing light, flexible systems and recommended the use of multi-degree-of-freedom coupled analysis methods in order to accurately represent the system's performance under blast loading. Wagner [24] presented numerical simulations of blast-resistant curtain walls and compared end rotations and ductility limits to test results. Wagner suggested that using more realistic failure criteria, 
in place of strict deformation limits, would produce well balanced structures, thus reducing the forces transferred to the supporting structure.

Limited full-scale tests have been performed on entire curtain wall systems. Nawar et al. [25] performed tests on two full-scale curtain wall systems using a shock tube and used the results to validate a FE model. Further, full-scale shock tube investigations by Baker Engineering and Risk Consultants were conducted to characterize the critical responses dictating the behavior of laminated glazing systems subjected to blast loads [26]. This test program was particularly significant due to the fact that the time histories of multi-directional glass edge reactions were recorded. The test results were compared to analytical glazing model predictions, particularly those by the Window Glazing Analysis Response and Design (WINGARD) established by the U.S. General Services Administration (GSA). The comparisons indicated that the existing codes generally predict glazing performances well; however, significant differences existed between the predicted glass reaction forces and the glass reaction forces measured during the tests.

The performance of glass curtain walls subjected to blast loads is a rapidly growing area of research in which several experimental and analytical studies have been documented recently. However, there has been limited open-arena blast testing of entire glazing systems reported in the literature. This paper addresses this need by presenting results from a series of openarena blast tests of three nearly-conventional glass curtain walls and documenting the development and results of a FE model that effectively represents the complex multi-physics response of glass curtain walls subjected to blast loading.

\section{EXPERIMENTAL PROGRAM}

\subsection{Curtain wall specimens}

Curtain wall specimens evaluated in the experimental program were nominally $3.66 \mathrm{~m}$ $(12 \mathrm{ft})$ tall, spanning vertically, and $2.44 \mathrm{~m}(8 \mathrm{ft})$ wide. Each specimen consisted of three $153 \mathrm{~mm}$ (6 in) deep split screw spline vertical aluminum mullions that were bridged together by six $153 \mathrm{~mm}$ (6 in) deep tubular screw spline horizontal aluminum mullions. The horizontal mullions were connected to the vertical mullions with four $25.4 \mathrm{~mm}$ ( $1 \mathrm{in})$ long screws through a predrilled hole in the vertical mullion and self-tapped into a receiving screw spline in the horizontal mullion. All mullions were manufactured by Kawneer NA. Four nominal $1.22 \mathrm{~m} \times 1.83 \mathrm{~m}(4 \mathrm{ft} \times 6 \mathrm{ft})$ laminated glass lites were attached to the aluminum extrusions with a $12.7 \mathrm{~mm} \times 6.4 \mathrm{~mm}(0.50 \mathrm{in} \times 0.25 \mathrm{in})$ GE SilPruf SCS 2000 structural silicone bead. Each of the lites comprised two $4.76 \mathrm{~mm}$ (3/16 in) annealed glass plies that were adhered to either side of a $1.52 \mathrm{~mm}(0.06 \mathrm{in})$ thick Solutia 060 PVB interlayer. The nominal thickness of the laminated glass layup was $11.05 \mathrm{~mm}(0.435 \mathrm{in})$. The elevation of all curtain wall specimens and the cross-section of the typical vertical mullions are shown in Fig. 1.

Due to handling safety and other practical considerations, the curtain wall specimens did not include an outboard glass lite (as is common in modern insulating glazing (IG) units) or an exterior pressure plate. Therefore, the specimens tested in this experimental program did not have the small additional stiffness (and energy absorption) provided by these two components. It is noted that the curtain wall specimens blast tested at the Infrastructure Security and Emergency Responder Research and Training (ISERRT) Facility were identical to those tested quasi-statically by Kennedy [1, 2]. 


\subsection{Test setup and instrumentation}

The curtain wall specimens were supported by a steel reaction frame as shown in Fig. 1. In order to replicate field conditions, each end of the vertical mullions was connected to the supporting structure with one $12.7 \mathrm{~mm}(1 / 2 \mathrm{in})$ diameter bolt that passed through double steel angles. The bottom connection angles had $1.59 \mathrm{~mm}$ (1/16 in) oversized holes and the top connection angles had $1.59 \mathrm{~mm}$ (1/16 in) oversized slots to allow for vertical in-plane movements.

The walls were instrumented with four flush-mount pressure transducers to measure the reflected pressures at different locations on the front face of the wall, and one shock transducer to measure accelerations at mid-height of the center vertical mullion; see Fig.1. The flush-mount pressure transducers were installed in steel plates with a nominal thickness of $6.4 \mathrm{~mm}(0.25 \mathrm{in})$ that were drilled and tapped to receive them. The plates were attached to the mullions using four $12.7 \mathrm{~mm}$ (1/2 in) bolts with $25.4 \mathrm{~mm}$ ( 1 in) spacers between the plate and the mullion to accommodate the transducer's cable; the plates were installed at connections of a horizontal and vertical mullion such that the transducer was located at approximately the corner of the glass lite at each respective location. The shock accelerometer was installed on the back of the center vertical mullion in a hole that was drilled and tapped to receive it. The accelerometer was oriented to measure the out-of-plane response of the wall. Two pencil probes, oriented perpendicular to each other, were used to measure the incident overpressures at approximately the same elevation as the center of gravity of the charge and at a $3.05 \mathrm{~m}$ (10 ft) standoff. High-speed video, where the field of view was oriented parallel to the wall's front face, was also obtained and used to supplement measuring dynamic wall deflections.

\subsection{Measured blast pressures}

All three specimens were subjected to two shots. For each shot, an explosive charge consisting of bundled sticks of UNIMAX (an extra gelatin dynamite manufactured by DYNO Nobel) was
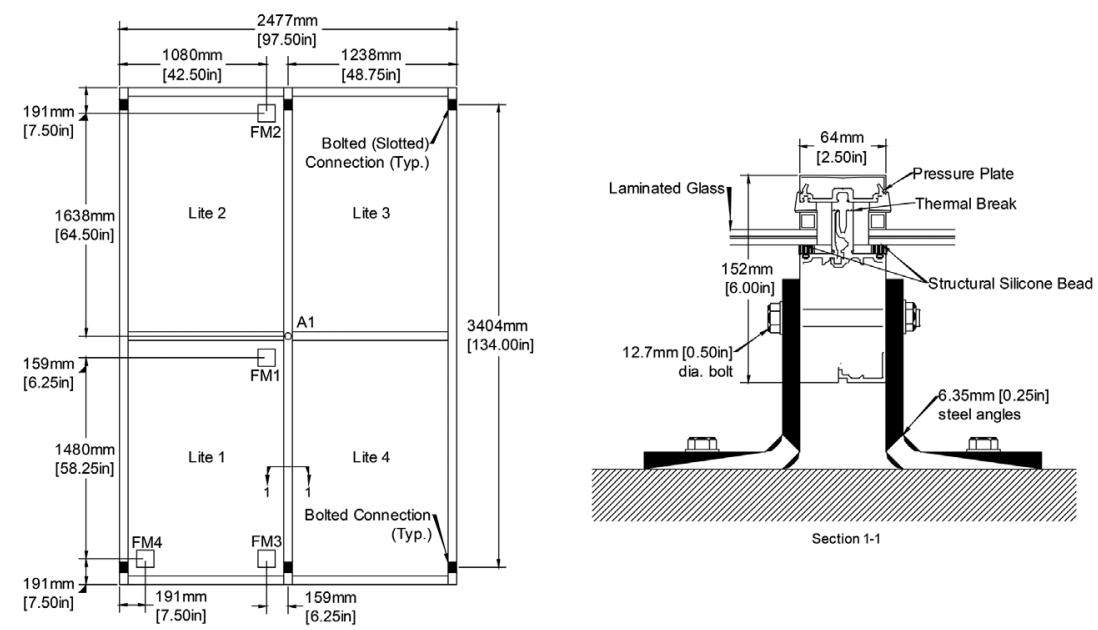

Figure 1: Elevation of curtain wall specimens (outside looking in) with flush-mount pressure (FM) and shock accelerometer (A) transducer locations shown; Section 1-1 shows a typical vertical mullion's cross-section and connection angles to the structural backup. 
placed in-line with the bottom center of the wall and detonated. The sticks were bundled symmetrically and the charge was oriented with its longitudinal axis vertical and parallel to the front face of the wall. The first shot for each specimen consisted of a very small charge detonated at a $9.14 \mathrm{~m}$ (30 ft) standoff; it was designed to test all transducers and the data acquisition system without causing damage to the curtain wall specimen. The second shot for each specimen consisted of a larger charge at a $1.83 \mathrm{~m}(6 \mathrm{ft})$ standoff and was intended to produce damage (inelastic response) within the curtain wall. The TNT equivalent weights and corresponding scaled distances for the second shot for each specimen were: $1.07 \mathrm{~kg}(2.35 \mathrm{lb})$ and $1.79 \mathrm{~m} / \mathrm{kg}^{1 / 3}\left(4.51 \mathrm{ft} / \mathrm{lb}^{1 / 3}\right)$ for Specimen $1,1.43 \mathrm{~kg}(3.15 \mathrm{lb})$ and $1.62 \mathrm{~m} / \mathrm{kg}^{1 / 3}\left(4.09 \mathrm{ft} / \mathrm{lb}^{1 / 3}\right)$ for Specimen 2, and $1.78 \mathrm{~kg}(3.92 \mathrm{lb})$ and $1.51 \mathrm{~m} / \mathrm{kg}^{1 / 3}\left(3.81 \mathrm{ft} / \mathrm{lb}^{1 / 3}\right)$ for Specimen 3 .

As described previously, incident and reflected overpressures produced by the blast wave were measured for each specimen. Due to limited damage produced from the lower charge weight used for Specimen 1 relative to Specimens 2 and 3, only the results from Specimens 2 and 3 are reported here. Representative plots of the reflected pressures and impulses (measured at transducer location FM3 as shown in Fig. 1) for Specimens 2 and 3 are shown in Fig. 2. Table 1 provides the peak reflected pressure, maximum (positive phase) reflected impulse, peak incident pressure and maximum (positive phase) incident impulse for each specimen.

\section{PERFORMANCE OF CURTAIN WALL SPECIMENS}

The purpose of the nearly-conventional curtain walls studied here was to economically provide additional blast resistance through simple modifications to a conventional curtain wall system. To economically achieve the most resistance, the curtain wall must safely sustain significant damage during the blast event in order to efficiently absorb and dissipate the blast energy. The curtain wall specimens examined here behaved similarly across all tests, possessing common damage patterns and failure mechanisms. These damage patterns included significant glass cracking and de-bonding of the glass from the mullions at the structural silicone joint. The mullions experienced no permanent deformation. Due to the location of the charges, much of the damage was concentrated in the lower half of
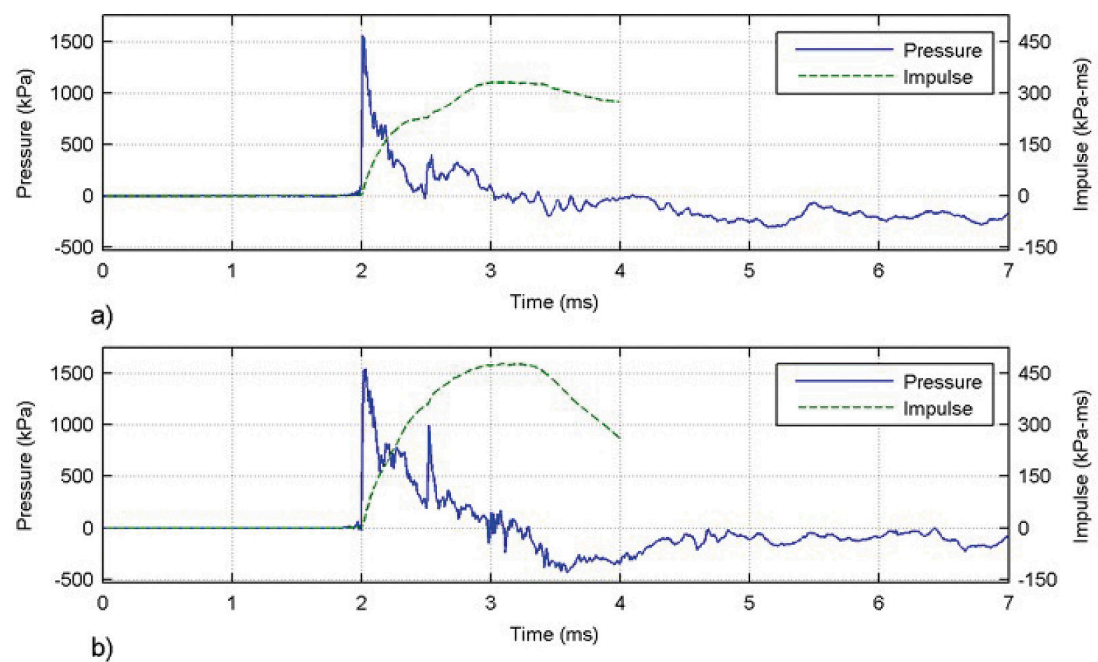

Figure 2: Reflected pressure and impulse measured at FM3: (a) Specimen 2 and (b) Specimen 3. 
Table 1: Peak reflected pressure, maximum reflected impulse, peak incident pressure and maximum incident impulse for each specimen.

\begin{tabular}{lcccc}
\hline Specimen & $\begin{array}{c}\text { Peak reflected } \\
\text { pressure, } \mathrm{kPa} \\
(\mathrm{psi})\end{array}$ & $\begin{array}{c}\text { Maximum } \\
\text { reflected impulse, } \\
\mathrm{kPa}-\mathrm{ms}(\mathrm{psi}-\mathrm{ms})\end{array}$ & $\begin{array}{c}\text { Peak incident } \\
\text { pressure, kPa } \\
(\mathrm{psi})\end{array}$ & $\begin{array}{c}\text { Maximum } \\
\text { incident impulse, } \\
\text { kPa-ms (psi-ms) }\end{array}$ \\
\hline 2 & $1556(225.8)$ & $330.9(48.00)$ & $142.0(20.60)$ & $98.60(14.30)$ \\
3 & $1542(223.7)$ & $476.4(69.10)$ & $200.6(29.10)$ & $57.20(8.30)$ \\
\hline
\end{tabular}

the specimens where the applied blast pressures were the greatest. Figure 3 shows Specimen 3 before and after the shot.

Most of the blast energy was dissipated through cracking and the ensuing large deformations of the laminated glass lites. During loading, the laminated glass lites initially exhibited plate-bending behavior up to fracture. After cracking, the glass transitioned into membrane behavior with the tensioned PVB interlayer contributing the majority of the remaining lateral stiffness. Significant glass cracking of all four lites was common to both specimens, and the maximum dynamic deflection of the center of a bottom lite was $139.7 \mathrm{~mm}$ (5.5 in) for Specimen 3 (obtained through high-speed video). The dynamic responses of the glass and the mullions were used to validate the FE model described later in this paper. Permanent deformations of the bottom halves of the lower glass lites were also observed. These blast test results demonstrated the effectiveness of using laminated (annealed) glass lites connected to conventional mullions with structural silicone sealant to resist low-level blast loads. The lower strength of annealed glass (relative to tempered glass) promoted glass fracturing into larger pieces, which remained adequately adhered to the PVB interlayer.

A significant failure mechanism observed in Specimen 3 was de-bonding of the glass from the mullion at the structural silicone sealant joint (tear-out). Tear-out resulted from a combined

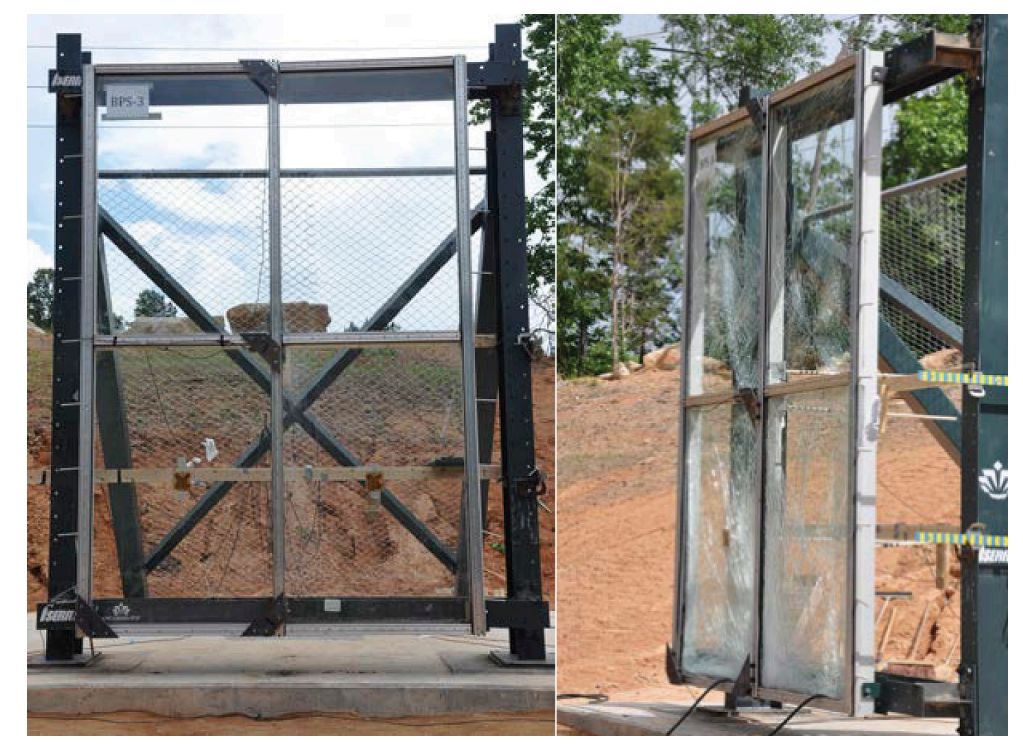

Figure 3: Specimen 3 before (left) and after (right) the shot. 
torsion and shear force interaction applied to the silicone bead by the glass as it underwent large deflections. As expected, the tear-out was most significant in the bottom halves of the lower lites. The tearing patterns observed during the tests suggested that the tear-out originated at the center of the lower horizontal edge and the center of the two vertical edges of the lower glass lites and progressed toward the bottom corners of the lites. The average horizontal and vertical tear-out lengths recorded for Specimen 3 were $645.2 \mathrm{~mm}$ (25.4 in) and $985.5 \mathrm{~mm}$ (38.8 in), respectively. Despite this tear-out and extensive glass cracking, all glass lites generally remained in place in the curtain wall; see Fig. 3. The tests demonstrated that this curtain wall system supplied adequate protection, approximately corresponding to the medium level of protection established in UFC 4-010-01 [27], when subjected to blast loads from a satchel-sized charge.

\section{NUMERICAL MODEL}

\subsection{Model description}

FE modeling of the entire curtain wall was performed using the commercial code LS-DYNA. The model included all of the components of one, full-scale curtain wall specimen with four glass lites, independent structural silicone sealant beads, and the supporting aluminum mullion framework; the vertical mullions were simply supported with a pin connection at the bottom and a roller connection at the top of each member. A convergence study was conducted on the system's internal energy and resulted in a $6.35 \mathrm{~mm}(0.25 \mathrm{in})$ module, indicating that mullion beam elements were $6.35 \mathrm{~mm}(0.25 \mathrm{in})$ long and glass lite shell elements were $6.35 \mathrm{~mm}(0.25 \mathrm{in})$ square. The elevation and cross-section of the model are shown in Fig. 4. All material and component properties used in the FE model, with the exception of the laminated glass, were experimentally determined in the testing program of a prior study [2].

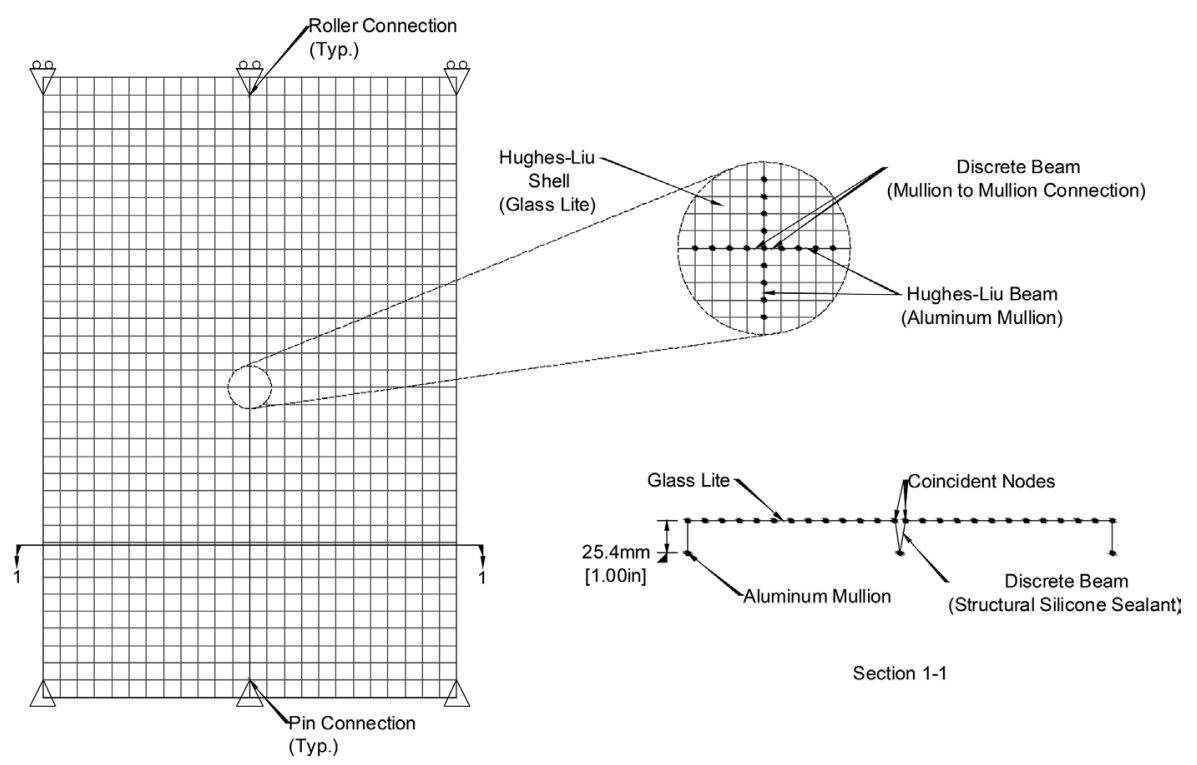

Figure 4: Elevation of the FE model (outside looking in); Section 1-1 is a section through the full width of the model. (Not to scale; coarse mesh shown for clarity.) 
The laminated glass lites were modeled with four-node shell elements using a laminated glass material model in LS-DYNA (i.e. MAT_LAMINATED_GLASS) [28]. This material model was chosen for its capability of capturing the glass and PVB interaction and allowing the user to define a failure strain for the glass such that, when a glass layer reached the failure strain, the stiffness contribution of that layer (not the entire element) would be deleted. No failure criterion could be assigned to the PVB interlayer, therefore its elastic deformations were unbounded. A dynamic increase factor (DIF) of 1.7 was applied to the nominal 'yield strength' of the glass to account for the increased apparent yield strength due to the high strain-rate effects resulting from the highly impulsive blast loading. This factor was within the bounds of tensile DIF's for annealed glass, proposed by Zhang et al. [29], for strain rates typical of those experienced during blast events.

The horizontal and vertical aluminum mullions were modeled using Hughes-Liu beams with the hollow box-shape cross-section option. Due to the complex cross-sectional geometry of the actual mullions, and the geometric limitations posed by the box section option, the dimensions of the hollow box section were chosen to most accurately reflect the section properties of the actual mullions. An elastic and kinematic strain hardening material model was used to model the aluminum. The connections between horizontal and vertical mullions were modeled using discrete beam elements that behaved as nonlinear springs. These elements occupied the first module at either end of the horizontal mullions; and each pertinent degree-of-freedom was given the appropriate stiffness and strength properties determined from full-scale static testing [2].

The structural silicone sealant was modeled with $25.4 \mathrm{~mm}$ (1 in) long discrete beam elements that functioned as nonlinear springs. This length, oriented perpendicular to the plane of the curtain wall, provided the correct offset of the glass relative to the center of mass of the mullions. For each element, all the pertinent degrees of freedom were given the appropriate stiffness and strength properties determined from testing [2]. A variance in the constructed bead size was observed in the specimens tested relative to the nominal size specified; therefore, the material properties of the spring model were adjusted to reflect a $4.76 \mathrm{~mm} \times 2.38 \mathrm{~mm}$ ( 0.19 in $\times 0.09$ in) silicone bead. This adjusted bead size was taken as the average constructed bead size over the entire specimen. In order to accurately model the response of an actual curtain wall system, the edge nodes of adjacent glass lites were not connected but, instead, were attached to separate structural silicone elements to allow for independent motions of the four glass lites.

Based on the $6.35 \mathrm{~mm}$ ( 0.25 in) module, the FE model consisted of 6720 beam elements, 221,184 shell elements and 225,985 nodes. Summaries of the material and component properties used in the FE model are provided in Tables $2-4$. Note that the structural silicone properties given in Table 4 are based on a $12.7 \mathrm{~mm} \times 6.4 \mathrm{~mm} \times 25.4 \mathrm{~mm}(0.50 \mathrm{in} \times 0.25$ in $\times 1$ in $)$ nominal bead.

\subsection{Application of measured blast pressures}

As outlined by Teich and Gebbeken [30], the effects of fluid-structure interaction (FSI) of the structural system with the blast wave can be significant for lightweight, flexible structures (such as curtain walls). Blast pressures applied to these types of structures can be significantly reduced due to large deformations. This interaction, and the corresponding reduction, is not captured when using rigid-wall loading assumptions common in available blast characteristics charts [31] and the LS-DYNA blast cards [32]. Therefore, to avoid this 
Table 2: Laminated glass material constants.

\begin{tabular}{lcc}
\hline Constant & Glass & PVB \\
\hline Young's modulus & $68.9 \mathrm{GPa}\left(10.4 \times 10^{6} \mathrm{psi}\right)$ & $5.74 \times 10^{-3} \mathrm{GPa}(833 \mathrm{psi})$ \\
Yield strength & $4.14 \times 10^{-2} \mathrm{GPa}(6000 \mathrm{psi})$ & $8.62 \times 10^{-3} \mathrm{GPa}(1250 \mathrm{psi})$ \\
Poisson's ratio & 0.22 & 0.40 \\
Tangent modulus & $0 \mathrm{GPa}(0 \mathrm{psi})$ & $1.920 \times 10^{-2} \mathrm{GPa}(2778 \mathrm{psi})$ \\
Plastic failure strain & $5 \times 10^{-6}$ & $\mathrm{~N} / \mathrm{A}$ \\
\hline
\end{tabular}

Table 3: Aluminum mullion material and mullion to mullion connection constants.

\begin{tabular}{lcc}
\hline Component & Property & Value \\
\hline Aluminum mullions & Young's modulus & $61.2 \mathrm{GPa}\left(8.87 \times 10^{6} \mathrm{psi}\right)$ \\
& Yield strength & $0.2410 \mathrm{GPa}(35,000 \mathrm{psi})$ \\
& Poisson's ratio & 0.3 \\
& Tangent modulus & $0.2460 \mathrm{GPa}(35,700 \mathrm{psi})$ \\
& Failure strain & 0.06 \\
Mullion to mullion & Elastic stiffness & $1.49 \times 10^{4} \mathrm{~N}-\mathrm{m} / \mathrm{rad}\left(1.32 \times 10^{5} \mathrm{lb}-\mathrm{in} / \mathrm{rad}\right)$ \\
connection & Yield moment & $366.0 \mathrm{~N}-\mathrm{mm}(3240 \mathrm{lb}-\mathrm{in})$ \\
& Tangent modulus & $7.66 \times 10^{3} \mathrm{~N}-\mathrm{m} / \mathrm{rad}\left(6.78 \times 10^{4} \mathrm{lb}-\mathrm{in} / \mathrm{rad}\right)$
\end{tabular}

Table 4: Structural silicone material constants.

\begin{tabular}{lccc}
\hline Constant & Normal & Shear & Rotation \\
\hline Elastic stiffness & $4.64 \mathrm{~N} / \mathrm{mm} / \mathrm{mm}$ & $0.322 \mathrm{~N} / \mathrm{mm} / \mathrm{mm}$ & $34 \mathrm{~N} / \mathrm{mm} / \mathrm{mm}$ \\
& $(673 \mathrm{lb} / \mathrm{in} / \mathrm{in})$ & $(46.70 \mathrm{lb} / \mathrm{in} / \mathrm{in})$ & $(7.6 \mathrm{lb} / \mathrm{in} / \mathrm{in})$ \\
Yield load & $9.20 \mathrm{~N} / \mathrm{mm}$ & $8.640 \mathrm{~N} / \mathrm{mm}$ & $14 \mathrm{~N} / \mathrm{mm}$ \\
& $(52.5 \mathrm{lb} / \mathrm{in})$ & $(49.36 \mathrm{lb} / \mathrm{in})$ & $(3.2 \mathrm{lb} / \mathrm{in})$ \\
Tangent modulus & $14.00 \mathrm{~N} / \mathrm{mm} / \mathrm{mm}$ & $3.83 \times 10^{-2} \mathrm{~N} / \mathrm{mm} / \mathrm{mm}$ & $3.1 \mathrm{~N} / \mathrm{mm} / \mathrm{mm}$ \\
& $(2030 \mathrm{lb} / \mathrm{in} / \mathrm{in})$ & $(5.55 \mathrm{lb} / \mathrm{in} / \mathrm{in})$ & $(0.7 \mathrm{lb} / \mathrm{in} / \mathrm{in})$ \\
Failure deflection & N/A & $30.8 \mathrm{~mm}(1.21 \mathrm{in})$ & $\mathrm{N} / \mathrm{A}$ \\
\hline
\end{tabular}

inaccuracy, the actual measured peak positive and negative phase pressures, impulses and blast wave arrival times recorded by the four flush-mount pressure transducers were used to define idealized blast waves that were applied to the curtain wall model. Applying idealized pressure pulses that were representative of the measured blast load took into account FSI effects and allowed for simple, yet accurate, modeling of the actual blast overpressures applied to the curtain wall (without the more complex computational fluid dynamics modeling of the blast wave propagating through air and its interaction with the flexible structure). 
As shown in Fig. 5a, blast pressures were applied to the FE model using 12 distinct pressure application regions; the number and dimensions of the regions were chosen to reasonably represent the number of locations on the face of the curtain wall where reflected pressures were measured. As is common in blast design and analysis, the complex waveform of the actual blast pressure trace was idealized with one or more triangular pressure pulses; see Fig. 5 b. The positive-phase blast pressure was represented by a triangular pressure pulse with an instantaneous rise time and linear decay, followed immediately by an inverted triangular pressure pulse with a finite rise time and finite decay that represented the negative phase blast pressure. The geometry of the idealized pressure pulses applied to each pressure application region was determined by linear interpolation (performed at the centroid of each region) of the measured pressures/impulses between the four transducer locations. Based on the measured trends, the negative phase impulse was taken as $50 \%$ of the positive phase impulse at all locations for all shots. A comparison of the measured reflected pressure time series to the modified Friedlander equation at each transducer location showed that this was a reasonable assumption for the charge weights and standoffs used during the tests. Pressure activation times were defined based on the location of the region relative to the charge to ensure an accurate representation of blast wave arrival times at each region over the front face of the curtain wall. Accurate representation of arrival times can be critical for capturing the differential movements experienced by very flexible systems subjected to blast loads.

\subsection{Damping}

Free vibration tests were conducted in order to determine the natural frequencies and structural damping ratios of the curtain wall specimens [2]. The damping ratios for the first three

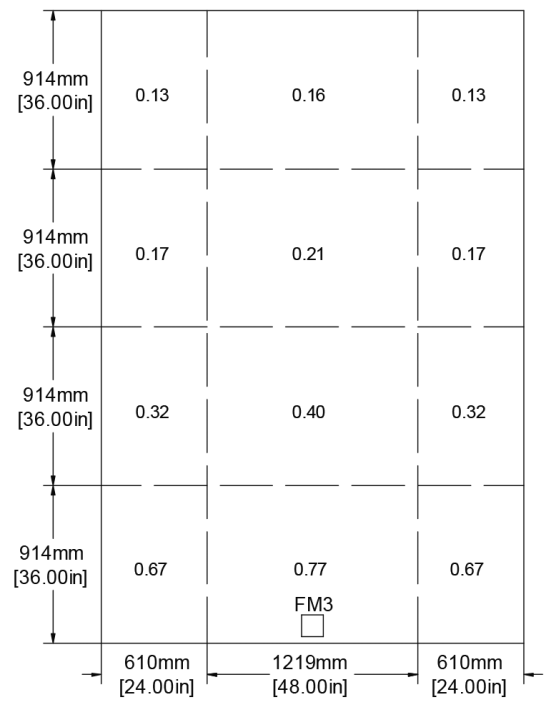

(a)

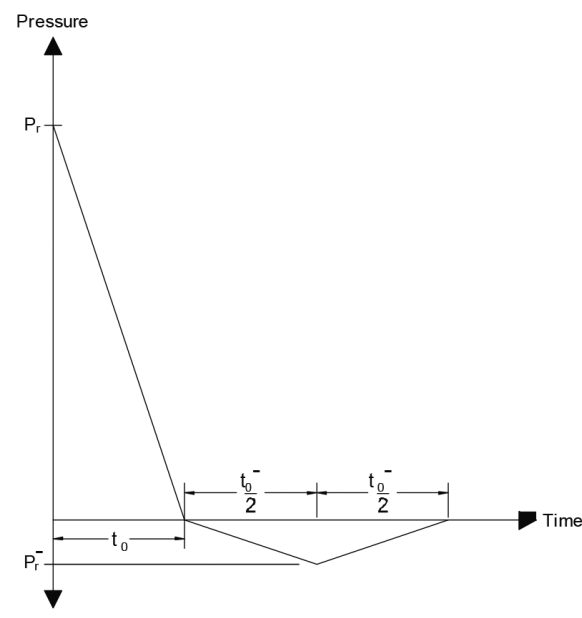

(b)

Figure 5: (a) Pressure application regions on the front face of the curtain wall and ratio of maximum impulses applied to each region relative to the maximum impulse measured at FM3; the charge was directly in-line with transducer FM3. (b) Typical idealized blast wave applied over the pressure application regions. 
modes of vibration that were symmetrical about both the horizontal and vertical axes were $13.84 \%$ at $10.68 \mathrm{~Hz}, 8.12 \%$ at $19.66 \mathrm{~Hz}$ and $5.58 \%$ at $36.09 \mathrm{~Hz}$. In the FE model, the structural damping of the curtain wall specimen was implemented with mass- and stiffness- weighted damping using the DAMPING_PART_MASS and DAMPING_PART_STIFFNESS features of LS-DYNA [32]. A mass-weighted damping constant equivalent to $13.4 \%$ of critical damping at the fundamental mode and a Rayleigh damping coefficient for stiffness weighted damping of 0.03 were used to represent structural damping.

The response of lightweight, flexible structures can be more accurately modeled if the total damping $\xi_{t}$ includes aerodynamic damping $\xi_{A}$ and FSI damping $\xi_{F S I}$ in addition to structural damping $\xi_{S}$, as shown in the following equation [30]:

$$
\xi_{t}=\xi_{s}+\xi_{A}+\xi_{F S I}=\left(\frac{a m}{2 \omega}+\frac{\beta \omega k}{2}\right)+\frac{c_{D} \rho c}{2 m_{s} \omega}+\frac{\rho c}{2 m_{s} \omega}
$$

where $\alpha$ and $\beta$ are the Rayleigh damping coefficients, $m$ is the mass of the curtain wall, $m_{\mathrm{s}}$ is its specific mass, $k$ is the stiffness of the curtain wall, $\omega$ is the fundamental natural circular frequency, $c_{\mathrm{D}}$ is the drag coefficient, $\rho$ is the ambient density of air and $c$ is the speed of sound in air.

A lightweight, flexible structure subjected to an extreme load experiences drag forces from the surrounding air it has to move as it deflects. The resulting energy dissipation is known as aerodynamic damping. As described by Teich and Gebbeken, the effects of aerodynamic damping can significantly influence the structural response of curtain walls subjected to blast loads. Therefore, aerodynamic damping should be applied, in addition to structural damping, to account for these aerodynamic effects (drag). The aerodynamic damping ratio used in the FE model was calculated using the second term of eqn (1), with properties of the curtain wall specimen given as: $c_{\mathrm{D}}=1.0, \rho=1.23 \mathrm{~kg} / \mathrm{m}^{3}\left(2.38 \times 10^{-3} \mathrm{lb}-\mathrm{s}^{2} / \mathrm{ft}^{4}\right), c=343 \mathrm{~m} / \mathrm{s}(1125 \mathrm{ft} / \mathrm{s})$, $m_{\mathrm{s}}=29.8 \mathrm{~kg} / \mathrm{m}^{2}\left(0.19 \mathrm{lb}-\mathrm{s}^{2} / \mathrm{ft}^{3}\right)$ and $\omega=67.7 \mathrm{rad} / \mathrm{s}$. An aerodynamic damping ratio, which was $10.4 \%$ of critical at the fundamental mode, was obtained and applied to the model as mass-weighted damping. FSI damping, the last term of eqn (1), was not used in the FE model, since the actual measured blast pressures (that inherently include this interaction) were used to load the model for all subsequent simulations.

Finally, it was observed that a portion of the structural damping, determined from the free vibration tests, was due to contributions of aerodynamic damping. However, given the smallamplitude deflections during the free vibration tests relative to those induced by blast loading, the contribution from aerodynamic damping to structural damping was determined to be insignificant and, therefore, was not accounted for twice.

\subsection{FE model validation}

The FE simulations were validated by comparisons to the open-arena test results of Specimens 2 and 3. The applied blast pressures for the simulations were interpolated from the corresponding pressures/impulses measured over each test specimen; therefore, the simulation for Specimen 3 involved higher pressures and impulses than the simulation for Specimen 2. Glass and mullion deflections, tear-out and glass cracking patterns predicted by the FE model were compared with the test results.

Figure 6 shows the simulated deflection time series of the center of Lite 1 (see Fig. 1 for lite numbering) for Specimen 3 along with the corresponding test results obtained through 
high-speed video. Similarly, Fig. 7 shows comparisons of the mid-height deflection time series of the center vertical mullion for both Specimens 2 and 3. The experimental mullion deflections are obtained by double integrating the acceleration time series measured at transducer A1; see Fig. 1. These comparisons show that the glass and mullion deflections of the simulations agree well with the test results. Figure 8 shows a comparison of the FE model to the high-speed video at 18 and $30 \mathrm{~ms}$ after the blast wave reaches the curtain wall. It is observed that the deflected profile of the glass predicted by the FE model compares reasonably well with the actual deflected profile captured by high-speed video. It is noted that, in the high-speed video capture, a part of the deflected profile of the glass is blocked by the mullion; the glass must deflect $101.6 \mathrm{~mm}$ (4 in) before it is visible behind the mullion due to the location of the back of the mullion relative to the glazing pocket; see Fig. 1. Conversely, the beam elements of the FE model do not possess cross-sectional dimensions; therefore, the full deflected profile of the glass is observed in the simulation.

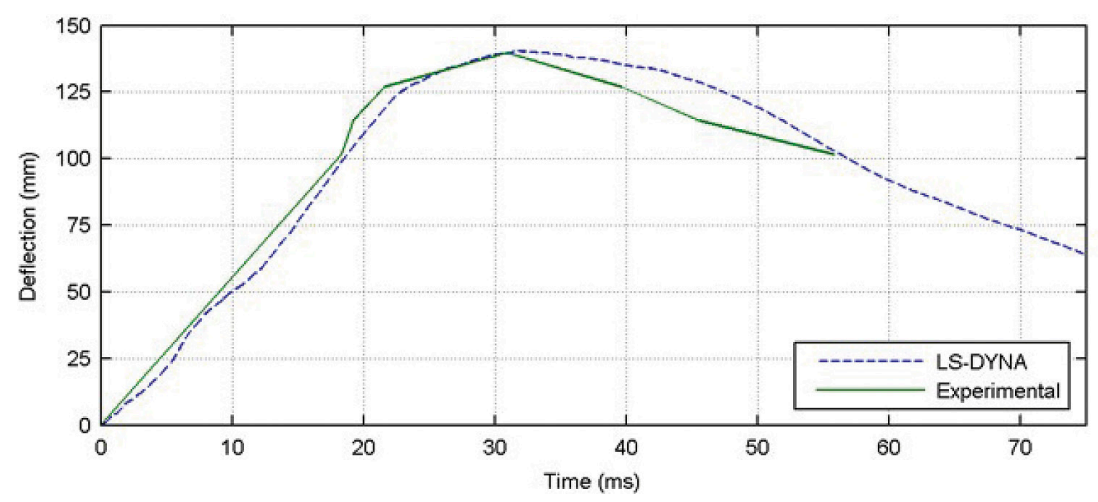

Figure 6: Comparison of deflection time series: center of Lite 1, Specimen 3.
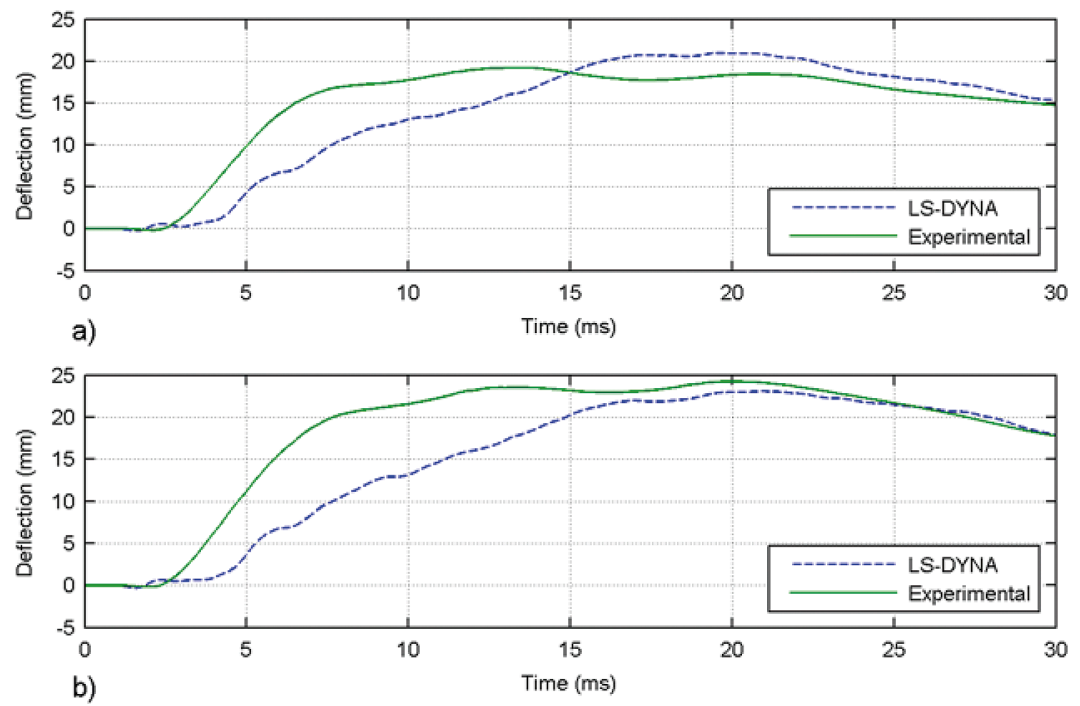

Figure 7: Comparison of mid-height deflection time series of center vertical mullion: (a) Specimen 2 and (b) Specimen 3. 

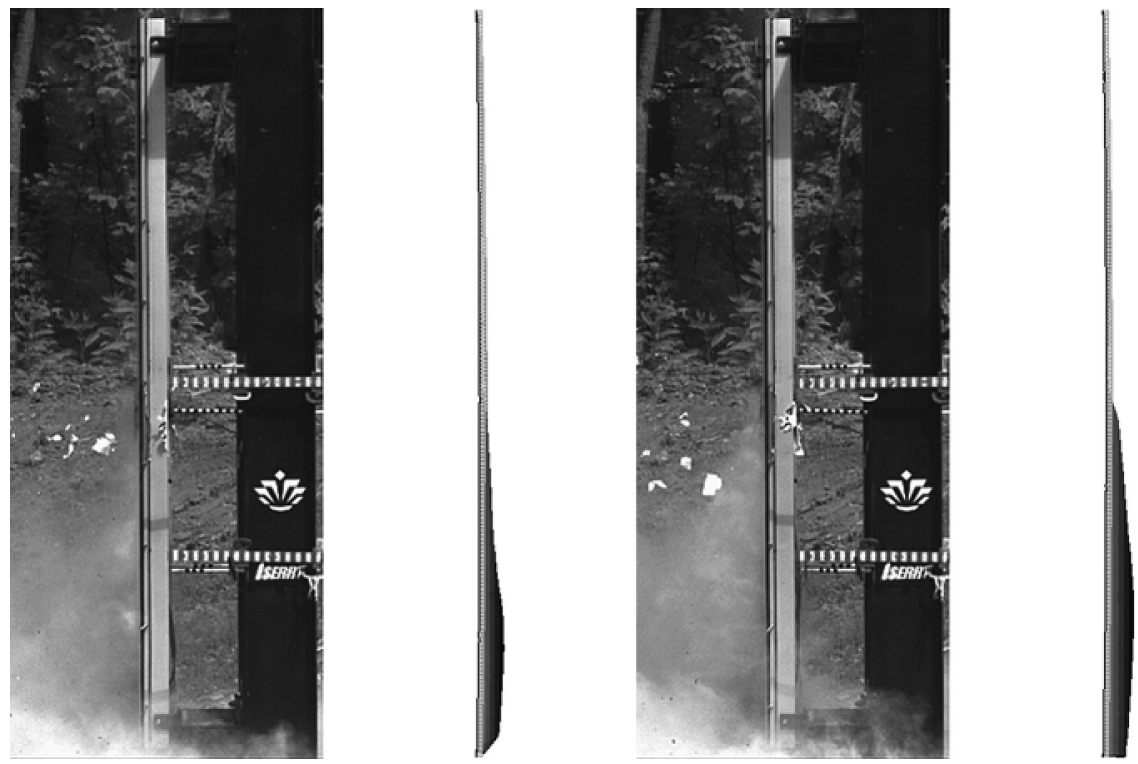

Figure 8: Comparison of the FE model to the high-speed video at $18 \mathrm{~ms}$ (left) and $30 \mathrm{~ms}$ (right) after the blast wave reaches the curtain wall.

As previously described, tear-out was observed only in Specimen 3, with average continuous horizontal and vertical tear-out lengths of $645.2 \mathrm{~mm}$ (25.4 in) and $985.5 \mathrm{~mm}$ (38.8 in), respectively. This behavior was accurately predicted by the FE model, where tear-out lengths and patterns agreed well with the test results. However, no tear-out was observed anywhere in Specimen 2, because the lower blast pressures from the smaller charge did not push the specimen to this limit state. Similarly, the FE model predicted no tear-out at any location in the model for the duration of the simulation. In both simulations, the FE model also predicted general glass cracking patterns with reasonable accuracy when compared to test results. Finally, when the model was subjected to the blast pressures corresponding to the small initial test shot applied to each specimen, no glass cracking (or other damage) was observed in the model.

\section{EVALUATION OF THE DESIGN EXPRESSION}

Kennedy et al. [1] outlined a simple procedure, suitable for initial design, in which an approximate curtain wall resistance function, combined with a simple nonlinear energy-based (equivalent spring) expression, could be used to estimate the blast resistance of a curtain wall system. The simple procedure was not proposed to take the place of glass fragmentation/ flight models used by the Department of Defense (DoD) and GSA [33, 34] for protective design of fenestration systems; rather, it was proposed to provide a rough estimate of the curtain wall's ability to be a protective barrier when a satisfactory resistance function is available for use. Kennedy et al. formulated an elastic-perfectly plastic resistance function for a nearly-conventional curtain wall system based on analytical expressions and the results of full-scale quasi-static tests that could be used in the design expression to approximate the maximum impulse the curtain wall could resist while remaining a protective barrier. The design expression is given by 


$$
i_{\max }=\sqrt{2 m} \sqrt{A_{r}}
$$

where $m$ is the effective mass of the system and $A_{\mathrm{r}}$ is the total area under the resistance function up to ultimate failure. For an elastic-perfectly plastic resistance function

$$
A_{r}=\frac{R_{m}{ }^{2}\left(\mu-\frac{1}{2}\right)}{k}
$$

where $R_{\mathrm{m}}$ is the maximum resistance of the curtain wall system, $\mu$ is its ductility and $k$ is its effective stiffness.

The curtain wall was judged to no longer serve as a protective barrier between the external threat and building occupants if any of the following three limit states were reached: fracture of an aluminum mullion, bolted or screwed connection failure or separation of glass lites from supporting mullions (tear-out) for a continuous length of $610 \mathrm{~mm}$ (24 in). For the nearly-conventional curtain wall systems investigated here and studied by Kennedy et al. [1], the properties of the curtain wall and the corresponding resistance function were: $R_{\mathrm{m}}=54.9$ $\mathrm{kN}\left(1.235 \times 10^{4} \mathrm{lb}\right), \mu=3.44, k=1.26 \mathrm{kN} / \mathrm{mm}\left(7.17 \times 10^{3} \mathrm{lb} / \mathrm{in}\right)$ and $m=320 \mathrm{~kg}\left(1.83 \mathrm{lb}-\mathrm{s}^{2} /\right.$ in). Using eqn (2) with eqn (3), and dividing the result by the frontal area of the curtain wall, an ultimate impulse of $238 \mathrm{kPa}-\mathrm{ms}$ (34.5 psi-ms) was predicted.

The validated FE model described in the previous section was used to evaluate the efficacy of the nonlinear design expression (when used with a satisfactory resistance function) in predicting the ultimate impulse that the curtain wall system could withstand before failure. The state of the model when subjected to a range of impulses was compared with the prediction of the design expression. Further, the failure modes in the simulations were compared with those observed in the quasi-static testing used to guide construction of the resistance function.

Since the design expression was derived assuming a uniformly applied impulsive load, it was evaluated by applying a uniformly distributed pressure impulse (i.e. a pressure pulse having a duration $1 / 20$ th of the curtain wall's fundamental period) to the front face of the curtain wall model; no negative phase pressures were included. This uniform pressure distribution is noted to be representative of a large charge at a distant standoff.

Half of the specimens in the quasi-static test program failed by fracture of the center vertical mullion at mid-height; the remaining specimens failed by reaching the maximum continuous length of tear-out [1]. However, due to the impulsive nature of the applied pressure, the FE simulations suggested that tear-out was the controlling failure limit state under low-level blast loading. Figure 9 shows the tear-out lengths predicted in the FE simulations as a function of the applied impulse. In the figure, the horizontal line denotes 'failure' (corresponding to the maximum allowable continuous tear-out length of $610 \mathrm{~mm}$ (24 in)) as defined by Kennedy et al. Interestingly, it is seen that the design expression (eqn (2)), though somewhat unconservative, does a surprisingly good job at predicting the failure impulse of the curtain wall system when compared with the FE simulations. The FE simulations predict a failure impulse of approximately $207 \mathrm{kPa}-\mathrm{ms}$ (30 psi-ms), which is 13\% lower than the failure impulse predicted by the design expression (238 kPa-ms (34.5 psi-ms)). The two data marker types in the figure denote whether the maximum tear-out predicted by the FE simulations is horizontal tearing along the mid-height horizontal mullions or vertical tearing along the vertical mullions. The plot shows that there is a range of impulses, just before the 
maximum tear-out transitions from horizontal to vertical, where the tear-out length is rather insensitive to change in impulse. This insensitivity could be attributed to the specific configuration of the curtain wall or to limitations inherent in the FE model, such as the simplified characterizations of mullion cross-sections and the structural silicone bead.

The maximum end rotation and mid-height deflection of the center vertical mullion predicted in the FE simulations under the ultimate impulse predicted by the design expression (238 kPa-ms (34.5psi-ms)) were $0.072 \mathrm{rad}\left(4.1^{\circ}\right)$ and $88.2 \mathrm{~mm}$ (3.5 in), respectively. Due to the difference in load duration, these values were somewhat smaller than the average values observed during the quasi-static tests reported in Kennedy et al. [1], which were $0.13 \mathrm{rad}$ $\left(7.5^{\circ}\right)$ and $137.2 \mathrm{~mm}$ (5.4 in), respectively. Figure 10 shows the deflected shape of the FE

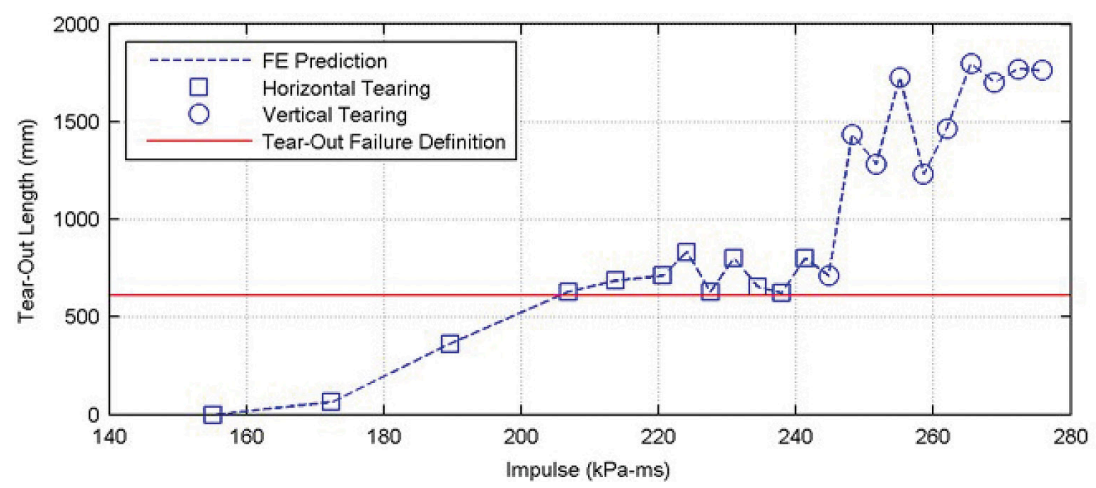

Figure 9: Continuous tear-out length versus applied impulse as predicted in the FE simulations.

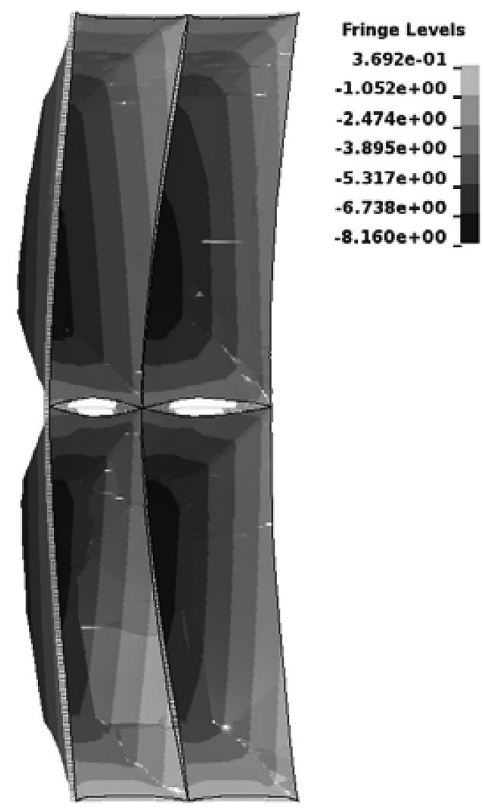

Figure 10: Deflected shape (corresponding to maximum tear-out) during an FE simulation with a $238 \mathrm{kPa}-\mathrm{ms}$ (34.5 psi-ms) impulse. (Note: Fringe levels are in units of inches.) 
model when it was subjected to the $238 \mathrm{kPa}-\mathrm{ms}$ (34.5psi-ms) impulse. Continuous tear-out of $622 \mathrm{~mm}$ (24.5 in) along both horizontal mullions (white regions) at mid-height is clearly visible in the figure.

\section{SUMMARY AND CONCLUSIONS}

Open-arena blast testing was performed to investigate the blast resistance of a nearlyconventional curtain wall system subjected to low-level blast loading. The tests demonstrated that this curtain wall system supplied adequate protection, approximately corresponding to the medium level of protection established by the $\mathrm{DoD}$, when subjected to blast loads from a satchel-sized charge.

The simplest adequate FE model was developed and validated with the test results. The nonlinear dynamic responses of the FE simulations, glass and mullion deflections, tear-out and glass cracking patterns, compared well with the test results. Although the model was intentionally kept as simple as possible, it effectively captured the complex responses of the curtain wall system and was reasonably computationally economical. Simulations of 0.1 seconds in duration, using 32 compute cores, required approximately $2 \mathrm{~h}$ of computational time. The FE simulations indicated that considerations such as: including negative phase blast pressures, aerodynamic damping and FSI can significantly affect the accuracy of modeling the structural responses of curtain walls. The simulations also indicated that high strain-rate effects, particularly in the glass, and the presence of high-frequency stiffness damping can affect the accuracy of the model.

The validated model was used to evaluate the efficacy of a simple nonlinear design expression to approximate the blast resistance of a curtain wall system. It was observed that tear-out was the controlling limit state when the curtain wall was impulsively loaded. Tear-out lengths from the FE simulations were provided for a range of applied impulses and the FE predicted failure impulse was compared to the maximum impulse predicted by the design expression. It was shown that the maximum impulse predicted by the design expression, when the expression was used in conjunction with a satisfactory resistance function, compared reasonably well with the FE simulation results. The expression could be used as a starting point for design or to supplement more advanced models of curtain walls subjected to blast loads.

\section{ACKNOWLEDGEMENTS}

Funding, in-kind services, and technical support for the testing programs presented in this paper were provided by Kawneer NA (Norcross, GA), an Alcoa subsidiary. Union Glass and Metal (Fort Mill, SC) donated the laminated glass and structural silicone sealant and assembled and transported the test specimens. The blast testing was conducted at the Infrastructure Security and Emergency Responder Research and Training (ISERRT) Facility (Gastonia, NC). Finally, the authors are grateful to Benjamin T. Kennedy for initial development of the FE model and his assistance with the early simulations.

\section{REFERENCES}

[1] Kennedy, B.T., Weggel, D.C. \& Keanini R.G., Experimental program and simplified nonlinear design expression for glass curtain walls with low-level blast resistance. International Journal of Computational Methods and Experimental Measurements, 1(3), pp. 321-343, 2013. doi: http://dx.doi.org/10.2495/cmem-v1-n3-321-343

[2] Kennedy, B.T., Performance of a nearly-conventional curtain wall system subjected to blast loads. Master's Thesis, University of North Carolina at Charlotte, Charlotte, NC, 2008. 
[3] Pascoe, L.M., Smith, D.C., Del Linz, P., Dear, J. \& Cormie, D., Development of a validated engineering model of laminated glass under blast loading. Proc. 2012 Struct. Cong., Chicago, IL, pp. 307-321, 2012. doi: http://dx.doi.org/10.1061/9780784412367.028

[4] Seica, M.V., Krynski, M., Walker, M. \& Packer, J.A., Analysis of dynamic response of architectural glazing subjected to blast loading. Journal of Architectural Engineering, 17(2), pp. 59-74, 2011. doi: http://dx.doi.org/10.1061/(asce)ae.1943-5568.0000035

[5] Lusk, B., Salim, H., Perry, K., Nawar, M., Wedding, W.C., Kiger, S. \& Ibrahim, A., Modeling and testing of laminated window systems under blast loading. Proc. 2011 Struct. Cong., Las Vegas, NV, pp. 1552-1560, 2011. doi: http://dx.doi. org/10.1061/41171(401)135

[6] Zhao, S., Dharani, L.R. \& Liang, X., Analysis of damage in laminated architectural glazing subjected to blast loading. Advances in Structural Engineering, 11(1), pp. 129-134, 2008. doi: http://dx.doi.org/10.1260/136943308784069432

[7] Lin, L.H., Hinman, E., Stone, H.F. \& Roberts, A.M., Survey of window retrofit solutions for blast mitigation. Journal of Performance of Constructed Facilities, 18(2), pp. 86-94, 2004. doi: http://dx.doi.org/10.1061/(asce)0887-3828(2004)18:2(86)

[8] Hooper, P.A., Sukhram, R.A.M., Blackman, B.R.K. \& Dear, J.P., On the blast resistance of laminated glass. International Journal of Solids and Structures, 49, pp. 899-918, 2012. doi: http://dx.doi.org/10.1016/j.ijsolstr.2011.12.008

[9] Kumar, P. \& Shukla, A., Dynamic response of glass panels subjected to shock loading.Journal of Non-Crystalline Solids, 357, pp. 3917-3923, 2011. doi: http://dx.doi. org/10.1016/j.jnoncrysol.2011.08.009

[10] Larcher, M., Solomos, G., Casadei, F. \& Gebbeken, N., Experimental and numerical investigations of laminated glass subjected to blast loading. International Journal of Impact Engineering, 39, pp. 42-50, 2012. doi: http://dx.doi.org/10.1016/j.ijimpeng.2011.09.006

[11] Wei, J., Shetty, M.S. \& Dharani, L.R., Stress characteristics of a laminated architectural glazing subjected to blast loading. Computers and Structures, 84, pp. 699-707, 2006. doi: http://dx.doi.org/10.1016/j.compstruc.2005.11.007

[12] Wei, J., Shetty, M.S. \& Dharani, L.R., Failure analysis of architectural glazing subjected to blast loading. Engineering Failure Analysis, 13, pp. 1029-1043, 2006. doi: http://dx.doi.org/10.1016/j.engfailanal.2005.07.010

[13] Wei, J. \& Dharani, L.R., Response of laminated architectural glazing subjected to blast loading. International Journal of Impact Engineering, 32, pp. 2032-2047, 2006. doi: http://dx.doi.org/10.1016/j.ijimpeng.2005.05.012

[14] Wei, J. \& Dharani, L.R., Fracture mechanics of laminated glass subjected to blast loading. Theoretical and Applied Fracture Mechanics, 44, pp. 157-167, 2005. doi: http:// dx.doi.org/10.1016/j.tafmec.2005.06.004

[15] Wei, Y., Suwen, C. \& Au, F.T.K., Failure analysis of four-point-supported glass panels subjected to blast loading. HKIE Transactions, 20(1), pp. 62-70, 2013.

[16] Zhang, X., Hong, H. \& Ma, G., Parametric study of laminated glass window response to blast loads. Engineering Structures, 56, pp. 1707-1717, 2013. doi: http://dx.doi. org/10.1016/j.engstruct.2013.08.007

[17] Yarosh, K., Wolf, A.T. \& Sitte, S., Evaluation of silicone sealants at high movement rates relevant to bomb mitigation window and curtainwall design. Journal of ASTM International, 6(2), pp. 1-17, 2009. doi: http://dx.doi.org/10.1520/jai101953

[18] Hautekeer, J.P., Monga, F., Giesecke, A. \& O’Brien, B., The use of silicone sealants in protective glazing applications. Glass Processing Days, Tampere, Finland, pp. 298-302, 2001. 
[19] Edel, M.T. \& Kumar, D., Blast design approach comparisons for curtain wall. Proc., 2010 Struct. Cong., Orlando, FL, pp. 2076-2089, 2010. doi: http://dx.doi. org/10.1061/41130(369)188

[20] Cussen, R. \& Van Eepoel, P., Inelastic dynamic finite-element design of glazed façade systems for blast loading. Crossing Borders: Structures Congress 2008, Vancouver, Canada, pp. 1-11, 2008. doi: http://dx.doi.org/10.1061/41016(314)153

[21] Dawson, H. \& Smilowitz, R., Inelastic dynamic response of curtainwall systems to blast loading. Journal of ASTM International, 4(5), pp. 1-5, 2007. doi: http://dx.doi. org/10.1520/jai100481

[22] Clift, C.D., Curtain wall designs for wind and blast: three case studies. Journal of Architectural Engineering, 12(3), pp. 150-155, 2006. doi: http://dx.doi.org/10.1061/ (asce)1076-0431(2006)12:3(150)

[23] Field, C.J., Godinho, J.A. \& Wopschall, S.R., Blast performance of cable supported curtain walls. Proc. 2012 Struct. Cong., Chicago, IL, pp. 322-332, 2012. doi: http:// dx.doi.org/10.1061/9780784412367.029

[24] Wagner, M., Nonlinear dynamic finite element analysis of blast loaded curtain walls. Proc., 2010 Struct. Cong., Orlando, FL, pp. 2090-2100, 2010. doi: http://dx.doi. org/10.1061/41130(369)189

[25] Nawar, M., Salim, H., Lusk, B. \& Kiger, S., Numerical simulation and verification of curtain wall systems under shock pressure. Practice Periodical on Structural Design and Construction, 19, pp. 1-12, 2014. doi: http://dx.doi.org/10.1061/(asce)sc.19435576.0000193

[26] Idriss, J.S. \& Lowak, M.J., Empirical evaluation of glazing systems in response to blast loads. Proc. 2014 Struct. Cong., Boston, MA, pp. 258-269, 2014. doi: http://dx.doi. org/10.1061/9780784413357.024

[27] UFC 4-010-01, DoD minimum antiterrorism standards for buildings. Department of Defense, Washington, DC, 2013.

[28] LS-DYNA R7.1 Keyword User's Manual, Vol. II Material Models; Livermore Software Technology Corporation, Livermore, CA, 2014.

[29] Zhang, X., Zou, Y., Hao, H., Li, X, Ma, G. \& Liu, K., Laboratory test on dynamic material properties of annealed float glass. International Journal of Protective Structures, 3(4), pp. 407-430, 2012. doi: http://dx.doi.org/10.1260/2041-4196.3.4.407

[30] Teich, M. \& Gebbeken, N., Structures subjected to low-level blast loads: analysis of aerodynamic damping and fluid-structure interaction. Journal of Structural Engineering, 138(5), pp. 625-635, 2012. doi: http://dx.doi.org/10.1061/(asce)st.1943$541 x .0000493$

[31] UFC 3-340-02. Structures to resist the effects of accidental explosions. Department of Defense: USA, 2008.

[32] LS-DYNA R7.1 Keyword User's Manual, Vol. I; Livermore Software Technology Corporation, Livermore, CA, 2014.

[33] PDC TR-12-01, Methodology manual for the single-degree-of-freedom blast effects design spreadsheet for windows (SBEDS-W). U.S. Army Corps of Engineers Protective Design Center Technical Report, 2012.

[34] ARA. WINGARD-MP (Multi-Pane Edition) User Guide. Applied Research Associates, 2010. 